\title{
SONOGRAPHICALLY DETERMINED ANOMALIES AND OUTCOME IN 170 CHROMOSOMALLY ABNORMAL FETUSES
}

\author{
JURIY W. WLADIMIROFF, WYDIA R. BHAGGOE, MIRANDA KRISTELIJN, TITIA E. COHEN-OVERBEEK, \\ NICOLETTE S. DEN HOLLANDER, HELEN BRANDENBURG AND FRANS J. LOS* \\ Division of Prenatal Diagnosis, Department of Obstetrics and Gynaecology; Department of Clinical Genetics*, \\ Academic Hospital Rotterdam-Dijkzigt, Rotterdam, The Netherlands
}

Received 29 June 1994

Revised 12 December 1994

Accepted 1 January 1995

\section{SUMMARY}

Structural pathology and outcome were studied in 170 chromosomally abnormal fetuses. Numerical chromosomal abnormalities were established in 158 ( 93 per cent) cases, of which 110 ( 71 per cent) represented trisomies, 30 (18 per cent) Turner syndrome, and 18 (11 per cent) triploidy. Structural chromosomal abnormalities were diagnosed in 12 (7 per cent) cases. Gestational age at referral was significantly shorter for pregnancies with Turner syndrome than for the other chromosomal abnormalities. Referral before 20 weeks of gestation was mainly based on fetal structural pathology alone ( 92 per cent); after 20 weeks, patients were referred because of structural pathology combined with small for gestational age, oligohydramnios, or polyhydramnios. Referral as a result of suspected multiple organ pathology occurred in 73.5 per cent of pregnancies. An abnormal amniotic fluid volume was present in 59/170 (34.5 per cent) chromosomally affected pregnancies, i.e., oligohydramnios in 31 and polyhydramnios in 28 cases. Birth weight was below the tenth percentile in over half of the chromosomally abnormal fetuses, except for Turner syndrome. Fetal outcome was poor, with a survival rate at 1 month of 30 per cent for trisomies which was mainly determined by trisomy $21(14 / 18=77 \cdot 5$ per cent $)$.

KEY WORDS: fetus; chromosomal anomalies; structural anomalies; oligohydramnios; polyhydramnios.

\section{INTRODUCTION}

The majority of chromosomally abnormal fetuses will present with single or multiple structural defects (Wladimiroff et al., 1985). Different chromosomal abnormalities may present with different subsets of anomalies. The effectiveness of anomaly scanning in low-risk populations has been variable, with detection rates between 40 and 85 per cent (Campbell and Smith, 1983; Saari-Kemppainen et al., 1990; Levi et al., 1991). This will determine the referral rate to a centre for prenatal diagnosis, where further sonographic analysis of the suspected anomalies and, if

Addressee for correspondence: J. W. Wladimiroff, MD, Ph.D., Department of Obstetrics and Gynaecology, Academic Hospital Rotterdam-Dijkzigt, Dr Molewaterplein 40, 3015 GD Rotterdam, The Netherlands. necessary, karyotyping will take place. Early detection of a chromosomal anomaly improves obstetric management, with termination of pregnancy as an option if a major chromosomal defect is found (Palmer et al., 1987; Rizzo et al., 1990).

The objective of the present study was to determine (i) the reasons for referral, (ii) the nature of the ultrasonographically detectable fetal structural pathology, and (iii) the fetal outcome in 170 chromosomally affected pregnancies.

\section{MATERIALS AND METHODS}

Between 1 January 1983 and 1 January 1993, 3840 pregnant women were referred from district hospitals to the Division of Prenatal Diagnosis of the Academic Hospital Rotterdam-Dijkzigt because of suspected fetal structural pathology 
alone or in combination with small for gestational age/oligohydramnios or polyhydramnios. Gestational age ranged between 15 and 37 weeks (mean 26 weeks) and was determined from the last menstrual period. In cases of uncertain dates or a discrepancy with ultrasound, the fetal crownrump length or biparietal diameter determined the gestational age.

A detailed anomaly scan was performed to determine the nature, extent, and severity of the structural anomaly and to identify possible associated malformations. Small for gestational age (SGA) was defined as an upper abdominal circumference below the tenth centile (Campbell and Wilkin, 1975) and/or a birth weight below the tenth centile according to the Kloosterman tables (Kloosterman, 1970), corrected for maternal parity and fetal sex. Oligohydramnios was defined as a largest fluid pool of $2 \mathrm{~cm}$ or less; polyhydramnios was defined as a largest fluid pool of $8 \mathrm{~cm}$ or more. Couples were counselled regarding the possible association with chromosomal defects and the risks and benefits of the different sampling procedures. Skeletal dysplasias and spina bifida without other structural pathology were the most common single-system anomalies for which karyotyping was not offered. The results of the ultrasound examinations and fetal karyotype were given to the referring obstetricians, who undertook the further management of the patients. Details on the outcomes of the pregnancies were obtained from the referring hospitals.

A total of 1410 patients opted for fetal karyotyping, of which 170 (12 per cent) demonstrated an abnormal fetal chromosome pattern. Data are presented from these 170 patients, in which cytogenetic analysis was carried out from amniotic fluid ( $n=101)$, chorionic villi $(n=33)$, or fetal blood $(n=36)$. Fifty-two patients refused fetal karyotyping, of which five delivered an infant with trisomy.

Statistical analysis was carried out using the Wilcoxon rank sum test for establishing differences in maternal and gestational age at referral between the various chromosomal anomalies. The chisquare test was used to compare the detection rate of chromosomal anomalies based on single-organ structural pathology before and after 20 weeks of gestation. This cut-off point was chosen since a fetal scan is advised at $16-20$ weeks by the professional organization in The Netherlands. An established screening programme, however, does not exist.

\section{RESULTS}

Numerical chromosomal abnormalities were found in 158 (93 per cent) cases, of which 17 (11 per cent) were trisomy 13,51 (33 per cent) trisomy 18,42 (27 per cent) trisomy 21,30 (18 per cent) Turner syndrome, and 18 (11 per cent) triploidy. Structural chromosomal abnormalities were diagnosed in 12 ( 7 per cent) cases (Table I). All chromosomal anomalies were confirmed postnatally. Sonographically determined anomalies were confirmed postnatally, although there was slight misclassification within the affected organ system (for instance, partial vs. complete atrioventricular septal defect; meningocoele vs. meningomyelocoele) in 12 cases. Additional minor anomalies (small ventricular or atrial septal defect, oesophageal atresia, cleft palate, etc.) were missed in 11 cases.

The mean maternal age ( $\pm 1 \mathrm{SD}$ ) and the mean gestational age $( \pm 1 \mathrm{SD})$ for each of the chromosomal abnormalities at referral are shown in Table II. Maternal age at referral was significantly lower for Turner syndrome compared with trisomy 21 $(P<0.001)$ and trisomy $18(P<0.05)$. Also, maternal age in cystic hygroma associated with Turner syndrome ( $n=23 ; 28.9 \pm 4.4$ (SD) years) was significantly lower $(P<0.001)$ compared with cystic hygroma associated with trisomy $(n=14,36.4 \pm 5.6$ (SD) years). Gestational age at referral in Turner syndrome was significantly lower compared with trisomies 21 and $18(P<0.001)$, trisomy 13 and triploidy $(P<0.01)$, and structurally abnormal chromosomes $(P<0.001)$.

Reasons for referral to our division of prenatal diagnosis are given in Table III. Referral before 20 weeks of gestation took place in 64 (39 per cent) pregnancies and after 20 weeks in the remaining 106 (61 per cent) pregnancies. Before 20 weeks of gestation, referral was mainly based on fetal structural pathology alone $(59 / 64=92$ per cent); after 20 weeks, patients were referred because of structural pathology alone $(47 / 106=44$ per cent $)$ or structural pathology in combination with small for gestational age (SGA), oligohydramnios or polyhydramnios $(59 / 106=56$ per cent $)$.

Chromosome analysis was performed because of single or multiple structural anomalies (Table IV). Referral as a result of a suspected single-organ anomaly occurred in $45 / 170$ (26.5 per cent) pregnancies and as a result of suspected multiple-organ pathology in the other $125 / 170$ ( 73.5 per cent) pregnancies. An abnormal chromosome pattern 
Table I-Fetal structural chromosomal abnormalities in 12 pregnancies presenting with sonographic fetal malformations

\begin{tabular}{|c|c|c|}
\hline Type of chromosomal abnormality & $n$ & Fetal karyotype \\
\hline $\begin{array}{l}\text { Balanced familial reciprocal } \\
\text { translocation }\end{array}$ & 3 & $\begin{array}{l}\text { 46,XX,t(11;13)(q21;q22.2)pat } \\
46 . \mathrm{XY}, \mathrm{t}(1 ; 6)(\mathrm{q} 11 ; \mathrm{q} 21.3) \mathrm{pat} \\
46, \mathrm{XY}, \mathrm{t}(2 ; 19)(\mathrm{p} 16 ; \mathrm{q} 13.2) \mathrm{mat}\end{array}$ \\
\hline De novo reciprocal transloation & 2 & $\begin{array}{l}46, X X, t(1 ; 16)(q 21 ; q 24) \\
46, X Y, t(1 ; 18)(\mathrm{p} 21 ; \mathrm{q} 23)\end{array}$ \\
\hline $\begin{array}{l}\text { Unbalanced familial reciprocal } \\
\text { translocation }\end{array}$ & 4 & $\begin{array}{l}46, \mathrm{XY},-8,+\operatorname{rec}(8), \mathrm{t}(8 ; 11)^{*} \text { mat } \\
46, \mathrm{XX},-18,+\operatorname{der}(18), \mathrm{t}(7 ; 18)(\mathrm{q} 21 ; \mathrm{q} 21.3) \mathrm{mat} \\
47, \mathrm{XY},+\operatorname{der}(9), \mathrm{t}(6 ; 9)(\mathrm{q} 23 ; \mathrm{q} 21.2) \mathrm{mat} \\
46, \mathrm{XY},-7,+\operatorname{der}(7), \mathrm{t}(7 ; 12)(\mathrm{q} 34 ; \mathrm{p} 13) \text { pat }\end{array}$ \\
\hline $\begin{array}{l}\text { Unbalanced de novo reciprocal } \\
\text { translocation }\end{array}$ & 2 & $\begin{array}{l}46, X Y,-4,+\operatorname{der}(4) \\
\text { FISH: } 46, X Y,-4,+\operatorname{der}(4), t(4 ; 11) \\
46, X X,-15,+15 \mathrm{p}+ \\
\text { not further determined }\end{array}$ \\
\hline De novo deletion & 1 & $46, \mathrm{XX}, \operatorname{del}(5)(\mathrm{p} 15.2)$ \\
\hline
\end{tabular}

Fetal karyotype: $46, \mathrm{XY},-8,+\operatorname{rec}(8)(8 \mathrm{qter} \rightarrow 8 \mathrm{p} 23:: 11 \mathrm{p} 21 \rightarrow 11 \mathrm{qter}), \mathrm{t}(8 ; 11)$ mat.

Maternal karyotype: $46, \mathrm{XX}, t(8 ; 11)(8 \mathrm{q} 12 \rightarrow 8 \mathrm{p} 23:: 1 \mathrm{lq} 21 \rightarrow 1$ lqter; 1 lpter $\rightarrow 1121:: 8 \mathrm{q} 12 \rightarrow 8 \mathrm{q}$ ter $)$ mat (Los et al., 1992).

Table II-Maternal age $(X \pm \mathrm{SD})$ and gestational age $(X \pm \mathrm{SD})$ at referral in 170 chromosomally affected pregnancies

\begin{tabular}{lcccccc}
\hline & \multicolumn{3}{c}{ Trisomy } & $\begin{array}{c}45, X \\
(n=30)\end{array}$ & $\begin{array}{c}\text { Triploidy } \\
(n=18)\end{array}$ & $\begin{array}{c}\text { Structural chromosomal } \\
\text { abnormality }(n=12)\end{array}$ \\
\cline { 2 - 6 } & $13(n=17)$ & $18(n=51)$ & $21(n=42)$ & $28.6 \pm 4.3$ \\
\hline $\begin{array}{c}\text { Maternal age (years) } \\
(X \pm 1 \text { SD) }\end{array}$ & $30 \cdot 1 \pm 6 \cdot 2$ & $31 \cdot 3 \pm 5 \cdot 2$ & $33 \cdot 4 \pm 6 \cdot 1$ & $28 \cdot 6 \pm 4 \cdot 7$ & $28 \cdot 6 \pm 4 \cdot 2$ & $28 \cdot 2 \pm 4 \cdot 3$ \\
$\begin{array}{c}\text { Gestational age (week) } \\
(X \pm 1 \text { SD })\end{array}$ & $26 \cdot 1 \pm 7 \cdot 5$ & $25 \cdot 6 \pm 7 \cdot 7$ & $25 \cdot 7 \pm 7 \cdot 6$ & $19 \cdot 7 \pm 5 \cdot 1$ & $24 \cdot 6 \pm 5 \cdot 8$ & $27 \cdot 0 \pm 5 \cdot 5$ \\
\hline
\end{tabular}

was established in the presence of a single-organ anomaly in $26 / 64(40.5$ per cent) pregnancies referred before 20 weeks and in 19/106 (18 per cent) pregnancies referred after 20 weeks $\left(\chi^{2}=9 \cdot 4\right.$; $P<0.02$ ). For trisomies alone, this was $22 / 37=60$ per cent vs. $13 / 60=21 \cdot 5$ per cent $\left(\chi^{2}=19 \cdot 6\right.$; $P<0.0001$ ).

The nature of the structural anomalies for each of the chromosomal abnormalities is depicted in Table V. Abnormalities of the central nervous system, renal tract, gastrointestinal tract, heart, and skeleton constituted the majority of structural pathology and were associated with trisomies $(28 / 53=53$ per cent at $\leqslant 20$ weeks; $148 / 180=82$ per cent at $>20$ weeks), triploidy (100 per cent at $\leqslant 20$ weeks; $17 / 19=89$ per cent at $>20$ weeks), and structural chromosomal abnormalities (100 per cent). Within the group of trisomies, the following observations were made. Brain and neural tube abnormalities were mostly seen in trisomies 13 and 18 , with emphasis on bilateral choroid plexus cysts combined with other anomalies and spina bifida in trisomy 18 and emphasis on holoprosencephaly in trisomy 13. Cardiac septal defects (ventricular septal defect, complete atrial ventricular septal defect) were seen in trisomies 13,18, and 21, as well as tetralogy of Fallot in trisomy 18. Gastrointestinal anomalies consisted of duodenal atresia (double bubble image) in trisomy 21 , and omphalocoele was observed in trisomies 13 and 18 . 
Table III-Reasons for referral before and after 20 weeks of gestation in 170 chromosomally affected pregnancies

\begin{tabular}{|c|c|c|c|c|c|c|c|}
\hline & \multicolumn{3}{|c|}{ Trisomy } & \multirow{2}{*}{$\begin{array}{c}45, \mathrm{X} \\
(n=30)\end{array}$} & \multirow{2}{*}{$\begin{array}{c}\text { Triploidy } \\
(n=18)\end{array}$} & \multirow{2}{*}{$\begin{array}{l}\text { Structural } \\
\text { chromosomal } \\
\text { abnormality } \\
(n=12)\end{array}$} & \multirow{2}{*}{$\begin{array}{c}\text { Total } \\
(n=170)\end{array}$} \\
\hline & $13(n=17)$ & $18(n=51)$ & $21(n=42)$ & & & & \\
\hline \multicolumn{8}{|c|}{ Structural pathology } \\
\hline$\leqslant 20$ weeks & 5 & 18 & 13 & 19 & 3 & 1 & 59 \\
\hline$>20$ weeks & 8 & 9 & 16 & 7 & 4 & 3 & 47 \\
\hline \multicolumn{8}{|c|}{$\begin{array}{l}\text { Structural pathology+ } \\
\text { SGA/oligohydramnios }\end{array}$} \\
\hline$\leqslant 20$ weeks & - & 1 & - & 1 & 2 & 1 & 5 \\
\hline$>20$ weeks & 2 & 5 & 4 & 3 & 9 & 3 & 26 \\
\hline \multicolumn{8}{|c|}{$\begin{array}{l}\text { Structural pathology+ } \\
\text { polyhydramnios }\end{array}$} \\
\hline$\leqslant 20$ weeks & - & - & - & - & - & - & - \\
\hline$>20$ weeks & 2 & 18 & 9 & - & - & 4 & 33 \\
\hline
\end{tabular}

SGA $=$ Small for gestational age.

Table IV-The incidence of fetal single and multiple anomalies at referral before and after 20 weeks of gestation

\begin{tabular}{|c|c|c|c|c|c|c|c|}
\hline & \multicolumn{3}{|c|}{ Trisomy } & \multirow{2}{*}{$\begin{array}{c}45, \mathrm{X} \\
(n=30)\end{array}$} & \multirow{2}{*}{$\begin{array}{c}\text { Triploidy } \\
(n=18)\end{array}$} & \multirow{2}{*}{$\begin{array}{c}\text { Structural } \\
\text { chromosomal } \\
\text { abnormality } \\
(n=12)\end{array}$} & \multirow{2}{*}{$\begin{array}{c}\text { Total } \\
(n=170)\end{array}$} \\
\hline & $13(n=17)$ & $18(n=51)$ & $21(n=42)$ & & & & \\
\hline \multicolumn{8}{|l|}{$\begin{array}{l}\text { Referral } \leqslant 20 \text { weeks } \\
\text { Structural pathology }\end{array}$} \\
\hline $\begin{array}{l}\text { Single anomaly } \\
\text { Multiple anomalies }\end{array}$ & $\begin{array}{l}3 \\
2\end{array}$ & $\begin{array}{r}10 \\
9\end{array}$ & $\begin{array}{l}9 \\
4\end{array}$ & $\begin{array}{r}2 \\
18\end{array}$ & $\overline{5}$ & $\frac{2}{-}$ & $\begin{array}{l}26 \\
38\end{array}$ \\
\hline \multicolumn{8}{|l|}{$\begin{array}{l}\text { Referral > }>\text { weeks } \\
\text { Structural pathology }\end{array}$} \\
\hline $\begin{array}{l}\text { Single anomaly } \\
\text { Multiple anomalies }\end{array}$ & $\overline{12}$ & $\begin{array}{r}3 \\
29\end{array}$ & $\begin{array}{l}10 \\
19\end{array}$ & $\overline{10}$ & $\begin{array}{r}3 \\
10\end{array}$ & $\begin{array}{l}3 \\
7\end{array}$ & $\begin{array}{l}19 \\
87\end{array}$ \\
\hline
\end{tabular}

Skeletal anomalies were seen in trisomies 13,18 , and 21 , with emphasis on abnormal hand and foot position and facial cleft. Micrognathia was associated with trisomy 18 , while polydactyly was associated with trisomy 13. Renal tract pathology nearly always constituted bilateral hydronephrosis in association with trisomies 13, 18, and 21. Miscellaneous anomalies were diaphragmatic hernia, two-vessel cord, and oesophageal atresia. Cystic hygroma and fetal hydrops were associated with Turner syndrome $(31 / 50=62$ per cent at $\leqslant 20$ weeks; $14 / 27=52$ per cent at $>20$ weeks).

An abnormal amniotic fluid volume was found in $59 / 170(34.5$ per cent) chromosomally affected pregnancies. Oligohydramnios was present in 31 pregnancies, of which 23 ( 74 per cent) were in the referrals beyond 20 weeks of gestation. Oligohydramnios was diagnosed in only $5 / 110(4.5$ per cent) cases with trisomy, in $4 / 12$ (33 per cent) cases with structural chromosomal abnormality, in 10/29 (34.5 per cent) cases with Turner syndrome, and in $12 / 18$ (67 per cent) cases with triploidy. Polybydramnios was present in 28 cases, all beyond 20 weeks of gestation. Polyhydramnios was diagnosed in $2 / 18$ (11 per cent) cases with triploidy, in 23/110 (21 per cent) cases of trisomy, and in $3 / 12$ ( 25 per cent) cases with a structurally abnormal chromosome. 


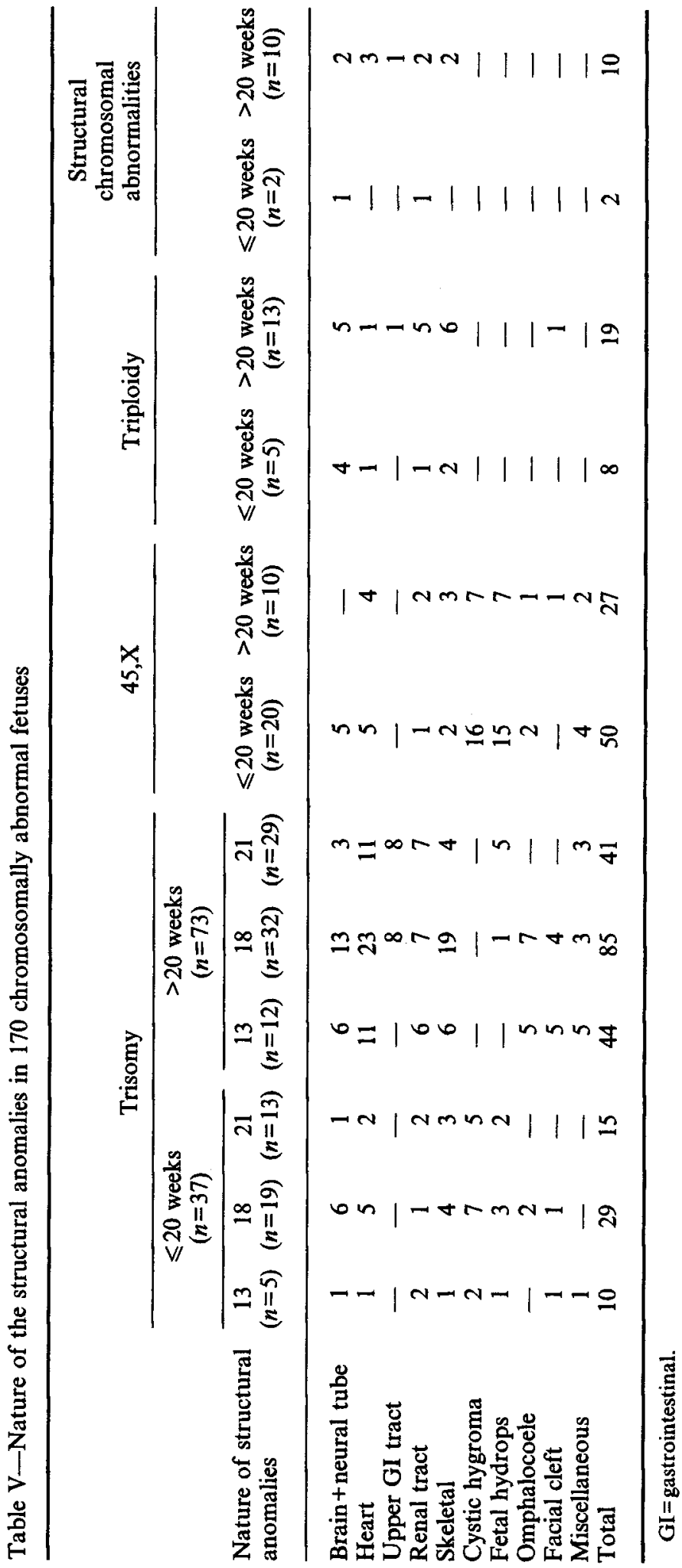


Table VI-Fetal outcome in 170 chromosomally affected pregnancies

\begin{tabular}{|c|c|c|c|c|c|c|}
\hline & \multicolumn{3}{|c|}{ Trisomy } & \multirow[b]{2}{*}{$\begin{array}{c}45, \mathrm{X} \\
(n=30)\end{array}$} & \multirow[b]{2}{*}{$\begin{array}{c}\text { Triploidy } \\
(n=18)\end{array}$} & \multirow{2}{*}{$\begin{array}{c}\text { Structural } \\
\text { chromosomal } \\
\text { abnomality } \\
(n=12)\end{array}$} \\
\hline & $\begin{array}{c}13 \\
(n=17)\end{array}$ & $\begin{array}{c}18 \\
(n=51)\end{array}$ & $\begin{array}{c}21 \\
(n=42)\end{array}$ & & & \\
\hline TOP & 9 & 26 & 14 & 26 & 14 & 6 \\
\hline IUD & 1 & 7 & 6 & 2 & 4 & - \\
\hline NND & 7 & 14 & 8 & - & - & 6 \\
\hline Alive at 1 month & - & 4 & 14 & 2 & - & - \\
\hline
\end{tabular}

TOP = Termination of pregnancy; IUD=intrauterine death; $N N D=$ neonatal death .

Birth weight was below the tenth percentile in $4 / 30$ (14 per cent) fetuses with Turner syndrome, in $6 / 12$ (50 per cent) fetuses with a structural chromosomal abnormality, in 58/110 (53 per cent) fetuses with trisomy, and in $16 / 18$ (90 per cent) fetuses with triploidy.

Perinatal outcome is presented in Table VI. Excluding the pregnancy terminations, the survival rate (at 1 month) for trisomies was $18 / 61$ (30 per cent), which was mainly determined by trisomy 21 $(14 / 18=77.5$ per cent). Of these 14 survivors with trisomy 21 , seven displayed no structural anomalies and the remaining seven cases were associated with duodenal atresia (2), duodenal atresia+ ventricular septal defect (VSD) (1), complete atrioventricular septal defect (1), hydrocephaly+VSD (1), and urethral obstruction +oligohydramnios (2). The neonatal survival rate was 50 per cent (2/4) for Turner syndrome and none for the remaining chromosomal abnormalities.

\section{DISCUSSION}

It should be emphasized that the present data represent a selected group of fetuses with chromosomal abnormalities and are not representative of chromosomally abnormal fetuses in general.

Despite the retrospective nature of the study, a number of comments can be made. Cordocentesis allows rapid karyotyping, which may be crucial during the late second and third trimesters of pregnancy when sudden decisions regarding obstetric management may have to be taken. Nevertheless, in over half of our cases, amniocentesis was performed. This was for the following reasons: (i) cordocentesis had not yet been introduced in our department before 1987; (ii) cordocentesis was not carried out in the presence of a small-for- gestational age (SGA) fetus due to the risk of further impairment of placental perfusion; (iii) cordocentesis often failed as a result of oligohydramnios or polyhydramnios.

The percentage of karyotyped patients with an abnormal chromosome pattern was 12 per cent, which is similar to that reported in the literature (Nicolaides et al., 1992). Numerical chromosomal abnormalities were established in the vast majority of cases ( 93 per cent), and in particular, trisomies.

Most chromosomal anomalies were diagnosed in referrals beyond 20 weeks of gestation, i.e., during the late second and early third trimesters of pregnancy. Apart from the psychological impact on the parents of such a late diagnosis, termination of pregnancy in cases of lethal fetal structural pathology is prohibited in The Netherlands beyond 24 weeks of gestation. Only fetuses with Turner syndrome were diagnosed earlier in pregnancy; 76 per cent (20/30) were found before 20 weeks. Unusual was the finding of five cases with Turner syndrome associated with central nervous system anomalies before 20 weeks: encephalocoele (1), hydrocephaly (2), and meningomyelocoele (2).

Diagnosis of this syndrome was mostly based on a combination of cystic hygroma and fetal hydrops, which produces well-defined sonographic images that are subject to early detection. This close association between cystic hygroma and fetal hydrops has also been reported by others (Azar et al., 1991). Cystic hygroma combined with fetal hydrops was also the most important marker for the early diagnosis of trisomy, especially trisomy 21 . However, the majority $(75 / 110=68$ per cent) of trisomies were detected by multiple structural anomalies during late gestation.

Of interest is the fact that in over half $(15 / 23=65$ per cent) of the cases with fetal cystic hygroma associated with Turner syndrome, the maternal 
age was below 30 years, as opposed to fetal cystic hygroma associated with trisomy, where the maternal age was more likely $(8 / 14=57$ per cent) to be 36 years or older.

In The Netherlands all women of 36 years and older are offered prenatal diagnosis. Approximately 30 per cent of these women do not undergo prenatal diagnosis for various reasons. In four out of eight women in the present study, the fetal cystic hygroma was established prior to a planned chorionic villus sampling or amniocentesis because of advanced maternal age. The remaining four women (one Dutch, three Mediterranean) did not undergo prenatal diagnosis for reasons unknown.

The reasons for the late diagnosis of chromosomal anomalies other than Turner syndrome are several: the apparent lack of clear guidelines as to whether and when to perform an anomaly scan in district hospitals and the limited capability of the referring institution to detect structural anomalies before 20 weeks of gestation. This is demonstrated by the fact that referrals before 20 weeks were predominantly based on a single-organ anomaly, whereas after 20 weeks an increasing number with multiple-organ pathology were diagnosed, as was particularly the case in trisomies. This higher pick-up rate of structural pathology after 20 weeks is due to the improved visualization of individual fetal structures as well as the appearance of associated pathology such as oligohydramnios and polyhydramnios later in gestation. It should be pointed out, however, that gastrointestinal pathology, in particular obstructive pathology, may not display itself sonographically until later in pregnancy; this was also demonstrated in the present study, in which none of the gastrointestinal lesions was detected before 20 weeks of gestation.

The majority of chromosomal abnormalities were associated with multiple structural anomalies. Whereas most chromosomal abnormalities had central nervous system, cardiac, renal tract, and skeletal defects in common, there were differences in the exact nature of the defects for the different chromosomal abnormalities. This was particularly so for central nervous system defects with bilateral choroid plexus cysts in trisomy 18 and holoprosencephaly in trisomy 13. Gastrointestinal anomalies were represented by duodenal atresia associated with trisomy 21. Additional pathology such as SGA and abnormal amniotic fluid volume played a minor role $(5 / 170=3$ per cent) in the early diagnosis of chromosomal anomalies. However, after 20 weeks of gestation structural pathology combined with SGA/oligohydramnios or polyhydramnios was the reason for referral in 15 per cent $(26 / 170)$ and 19 per cent (33/170) of cases, respectively.

Fetuses with triploidy were associated with oligohydramnios in 67 per cent but with normal amniotic fluid in 22 per cent and with polyhydramnios in 11 per cent of cases. There was, however, no difference in the nature of the structural anomalies between these two subsets. Polyhydramnios was seen in approximately 20 per cent of trisomies, mainly associated with gastrointestinal tract anomalies, and in 25 per cent of structurally abnormal chromosomes, mainly associated with skeletal, cardiac, and central nervous system pathology.

Birth weight was below the tenth centile for weight by gestation in at least half of the chromosomal anomalies, except for Turner syndrome due to the presence of hydrops and/or fluid in the cystic hygroma. In triploidy, birth weight was below the tenth centile for weight by gestation in 90 per cent of cases, which together with the high incidence of oligohydramnios (67 per cent) explains why half (9/18) of the triploidy cases were referred on the basis of combined structural pathology and SGA/oligohydramnios.

Fetal outcome in the presence of a chromosomal abnormality was poor; in our study, the neonatal survival rate was 12 per cent (20/170), which was mainly due to trisomy 21. Early diagnosis of structural pathology is therefore essential, since it will allow the availability of all modalities of obstetric management including pregnancy termination. In this study, termination of pregnancy took place in over half $(95 / 170)$ of the cases.

It can be concluded that referrals for anomaly scanning before 20 weeks are mainly based on single-organ pathology, whereas beyond 20 weeks they are based on both single- and multiple-organ pathology. Fetuses with Turner syndrome are referred at an earlier stage in pregnancy than fetuses with other chromosomal anomalies. This may be due to the well-defined pathology (cystic hygroma, fetal hydrops) as demonstrated by ultrasound. Cystic hygroma whether or not combined with fetal hydrops was also the most noticeable marker for the early diagnosis of trisomy with emphasis on trisomy 21 . Oligohydramnios is often associated with triploidy, whereas polyhydramnios occurs with trisomies, in particular in gastrointestinal anomalies with trisomy 21 . The sonographic identification of structural anomalies for screening 
chromosomal aberrations was of limited value, because of either late diagnosis or the high fatality rate of the lesions. The late diagnosis is partly determined by the lack of an established national sonographic screening programme below 20 weeks of gestation in The Netherlands.

\section{REFERENCES}

Azar, G., Snijders, R.J.M., Gosden, C.M., Nicolaides, K.H. (1991). Fetal nuchal cystic hygromata; associated malformations and chromosomal defects, Fetal Diagn. Ther., 6, 46-57.

Campbell, S., Smith, P. (1983). Routine screening for congenital abnormalities by ultrasound. In: Rodeck, C.H., Nicolaides, K.H. (Eds). Prenatal Diagnosis. Proceedings of the 11th Study Group of the Royal College of Obstetricians and Gynaecologists, London: Royal College of Obstetricians and Gynaecologists, 325-330.

Campbell, S., Wilkin, D. (1976). Ultrasonic measurement of fetal abdominal circumference in estimation of fetal weight, Br. J. Obstet. Gynaecol., 82, 689-697.

Kloosterman, G.J. (1970). On intrauterine growth, Int. J. Gynaecol. Obstet., 8, 895-912.

Levi, S., Hyjazi, Y., Schaaps, J.P., Defoort, P., Coulon, R., Buekens, P. (1991). Sensitivity and specificity of routine antenatal screening for congenital anomalies by ultrasound; the Belgian Multicenter Study, Ultrasound Obstet. Gynecol., 1, 102-110.

Los, F.J., Hagenaars, A.M., Marrink, J., CohenOverbeek, T.E., Gaillard, J.L.J., Brandenburg, H. (1992). Maternal serum alpha-fetoprotein levels and fetal outcome in early second trimester oligohydramnios, Prenat. Diagn., 12, 285-292.

Nicolaides, K.H., Snijders, R.J.M., Gosden, C.M., Berry, C., Campbell, S. (1992). Ultrasonically detectable markers of fetal chromosomal abnormalities, Lancet, 1, 704-707.

Palmer, C.G., Miles, J.H., Howard-Peebles, P.N., Magenis, R.E., Petil, S., Friedman, J.M. (1987). Fetal karyotype following ascertainment of fetal anomalies by ultrasound, Prenat. Diagn., 7, 551-555.

Rizzo, N., Pitalis, M.C., Pilu, G., Orsini, L.F., Perolo, A., Bovicelli, L. (1990). Prenatal karyotyping in malformed fetuses, Prenat. Diagn., 10, 17-23.

Saari-Kemppainen, A., Karjalamen, O., Ylostalo, P., Heinone, O.P. (1990). Ultrasound screening and perinatal mortality: controlled trial of systematic onestage screening in pregnancy, Lancet, 336, 387-391.

Wladimiroff, J.W., Stewart, P.A., Sachs, E.S., Niermeijer, M.F. (1985). Prenatal diagnosis and management of congenital defects; significance of associated fetal anomalies and prenatal chromosome studies, Am. J. Med. Genet., 212, 285-290. 